\title{
Por Trás do Que Você Vê: Rock, Ação Cultural e Espaços Híbridos na Cidade
}

\author{
Behind What You See: Rock, Cultural Action and Hybrid Spaces in the City
}

\author{
Denise Mônaco dos Santos \\ Nomads.usp \\ Universidade de São Paulo, Brasil \\ demonaco@sc.usp.br \\ Marcelo Tramontano \\ Nomads.usp \\ Universidade de São Paulo, Brasil \\ tramont@sc.usp.br
}

\author{
Alison Henrique Nasario \\ Nomads.usp \\ Universidade de São Paulo, Brasil \\ alisontio@gmail.com
}

\begin{abstract}
This paper presents the development and results of interventions in urban spaces using two graphic interactive interfaces, Backstage and Comments. They were implemented during cultural actions carried out as part of the 'Hybrid Territories project: digital media, communities, and cultural actions' developed by Nomads.usp, University of São Paulo, Brazil. It consists of events aiming to explore the creation of hybrid situations in urban fragments so as to enrich them in multiple ways, but mainly from a sociocultural perspective.
\end{abstract}

Keywords: Urban interfaces; Social interactions; Hybrid spaces.

\section{Introdução}

As discussões a respeito da criação de espaços híbridos em fragmentos urbanos consideram os espaços constituídos a partir da inserção de comunicação mediada por sistemas computacionais em porções da cidade. Inúmeras possibilidades e potencialidades de configuração desses espaços se desenham a partir de um processo de mediação construído na confluência de lugares, pessoas e tecnologias digitais (Foth, Choi \& Satchell, 2011). As interfaces pensadas para espaços urbanos incluem projeções em edifícios e outras superfícies urbanas, fachadas interativas, a arquitetura agregada a sistemas interativos, os displays implantados em espaços urbanos ou integrados em fachadas e, ainda, interfaces com superfícies interativas multitouch móveis.

Esse artigo apresenta o desenvolvimento e alguns resultados de experiências voltadas a esta temática, levadas a cabo pelo projeto Territórios Híbridos: meios digitais, comunidades e ações culturais, realizado pelo Nomads.usp Núcleo de Estudos de Habitares Interativos do Instituto de Arquitetura e Urbanismo, da Universidade de São Paulo, Brasil. Esse projeto teve como objetivo maior explorar a construção de espacialidades híbridas a partir de ações de cunho cultural com uso de meios digitais, voltadas a estimular o reconhecimento e a valorização de diversidades culturais e sociais.

As experiências em questão envolveram o uso de duas interfaces computacionais, especialmente desenhadas, em eventos culturais com apresentação de uma banda de rock em contextos urbanos distintos. Tais eventos culturais estiveram inscritos dentro de uma ação cultural ampla do projeto Territórios Híbridos, chamada Backstage, com objetivos múltiplos, implementada entre dezembro de 2012 e março de 2013. Grosso modo, tal ação buscava [1] expor modos independentes de produção cultural na área musical, em especial aqueles ligados ao rock; [2] explorar potencialidades e aplicações de meios digitais em intervenções musicais presenciais - em espaços públicos - e remotas, através do uso da internet; [3] utilizar o modus operandi de coletivos ligados ao Circuito Fora do Eixo em diferentes lugares do Brasil; [4] promover a vivência da banda nesses coletivos, focando nas experiências advindas de uma circulação que envolve cidades, hábitos, públicos e contextos culturais eventualmente diferentes, em diferentes regiões do país; e [5] provocar reflexões no público sobre gêneros musicais que, em princípio, não fazem parte de suas escolhas, promovendo estranhamentos ao organizar apresentações da banda de rock em locais onde esse gênero não costuma ser bem aceito.

A ação Backstage foi implementada com a circulação da banda de rock Topsyturvy por três cidades do estado do Rio Grande do Sul Pelotas, Caxias do Sul e Porto Alegre; por diferentes lugares da cidade de São Paulo - por exemplo, na Rua Augusta, centro da cidade, e no distrito Cidade Tiradentes, periferia da zona leste paulistana; e também na cidade de São Carlos. Além das intervenções musicais em espaços públicos com o uso das duas interfaces, chamadas Backstage e Comentários, também foram realizadas discussões transmitidas por livestream, jam session 
remota, atividades nas quais os meios digitais também são centrais.

Nesse sentido, ressalta-se que, além de atividades de diferentes naturezas realizadas simultaneamente, houve uma diversidade de temas abordados nessa ação, dos quais derivam múltiplos resultados. Esse artigo apresenta resultados sobre as experiências de uso das interfaces Backstage e Comentários nas intervenções nos espaços públicos urbanos dessa ação cultural.

\section{Interfaces e Interações no Espaço Urbano}

Esse trabalho considera intervir na escala de comunidades, de grupos de pessoas que se vinculam a determinados lugares inscritos em porções da cidade, em fragmentos urbanos, seja a partir de um caráter mais permanente ou efêmero. Nesse sentido, as interfaces digitais, como suportes tecnológicos lógicos e físicos, são direcionadas no sentido da possibilidade de dotar essas comunidades locais, ou grupos de pessoas reunidos em eventos, de um locus híbrido, adensando esferas de comunicação e interação. Trata-se de uma incursão nas qualidades das interfaces como meio, como canal, através dos quais relações entre pessoas e grupos também possam se estabelecer.

Assim, as interações são entendidas aqui tanto a partir de ações e relações entre membros de uma comunidade ou grupo, com foco na qualidade dessas relações estabelecidas entre indivíduos e, em certo sentido, nos seus desdobramentos. As interfaces mediam essas interações ao mesmo tempo em que se apresentam como sistemas que pressupõem também interações, ou seja, conjuntos de ações e relações específicas, próprias ao domínio dos artefatos computacionais e digitais (Bolter \& Gromala, 2003; Preece; Rogers \& Sharp, 2005). Essas duas abordagens, sem e com mediação digital, reforçam o caráter interdisciplinar que envolve pesquisas dessa natureza, que procuram relacionar a qualidade das experiências mediadas por interfaces computacionais com as próprias características e configurações dessas interfaces.

As duas interfaces, Backstage e Comentários, implementadas, ora separadas, ora em conjunto, nos eventos culturais aqui considerados, estabeleceram novos layers de comunicação entre os sujeitos participantes, sejam público, artistas, produtores culturais e outros parceiros envolvidos. A implementação dessas duas interfaces nesse contexto teve, antes de tudo, o objetivo de fomentar e explorar novos processos comunicativos e interativos, tornar transparentes informações não pronunciadas, declaradas, ampliando possibilidades de interações, trocas e vivências no espaço público urbano. As intervenções urbanas aqui tratadas consideram a prerrogativa de se ter o público, isto é, os sujeitos urbanos como produtores de conteúdo, como participantes ativos e não passivos, como agentes sociais e culturais, e não apenas como espectadores. Nesse sentido, buscam qualificar espacialidades híbridas a partir de uma perspectiva relevante de um ponto de vista sociocultural.

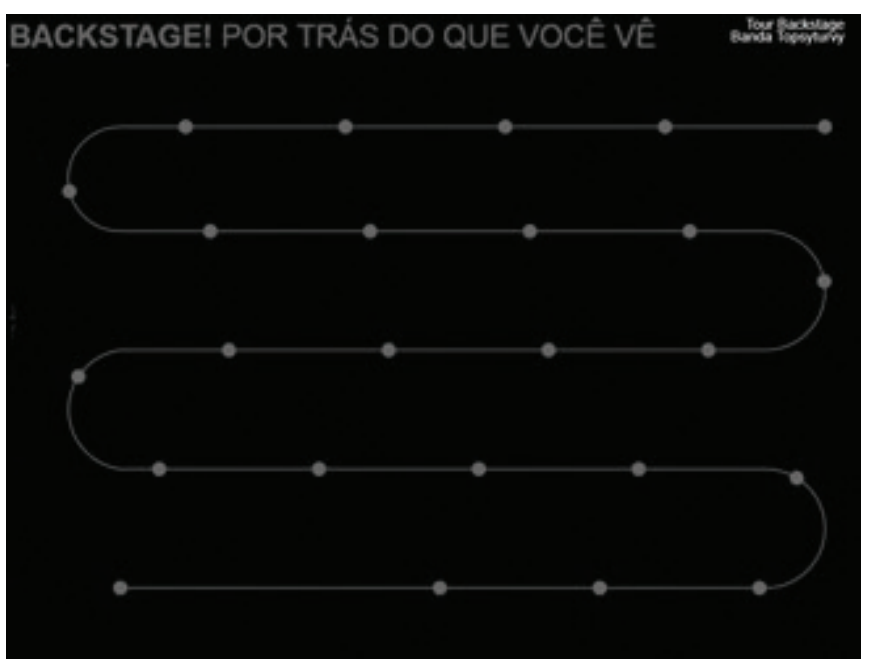

Figura 1: Interface Backstage especialmente desenhada para a ação do projeto Territórios Híbridos, chamada também ação Backstage. Fonte: Nomads.usp.

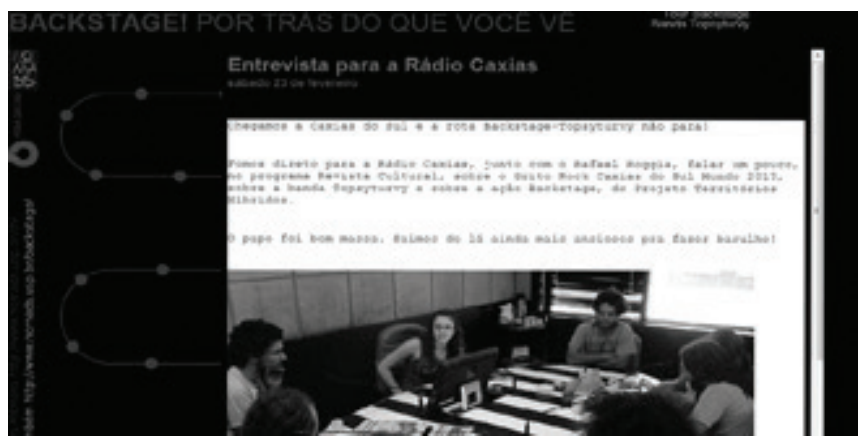

Figura 2: Interface Backstage com informações sobre atividades realizadas em Caxias do Sul. Fonte: Nomads.usp.

\section{Interface Backstage: a Transparência dos Processos}

A interface de base web chamada Backstage [www.nomads.usp.br/backstage] cumpre a função de agrupar informações sobre o processo de produção de eventos culturais, independentemente das configurações e formatos que possam assumir, embora as experiências aqui contextualizadas digam respeito a apresentações de uma banda de rock. A interface corresponde a uma espécie de linha do tempo que é construída assincronicamente durante o processo de produção cultural, a partir de inputs de todos os agentes envolvidos nesse processo, que podem constituir informações sobre diferentes etapas de trabalho, tarefas, atividades e realizações, ou ainda, impressões sobre situações e experiências. O objetivo principal desse registro é tornar o processo de produção de uma ação cultural transparente ao público, revelar a esse público o que está por trás do que ele vê no palco. A forma como isso se efetiva é justamente quando a interface é disponibilizada para interação das pessoas em eventos, e quando ainda, essas interações são projetadas e compartilhadas com todos os presentes num dado espaço.

A ideia que impulsiona a aspiração de tornar transparente para o público tais processos parte de um entendimento de que ações 
culturais devem, antes de tudo, estar ligadas a possibilidades de alteração de repertórios e de construção de autonomias cognitivas e protagonismos que possam reverberar em transformações em diferentes níveis, mas principalmente, que podem colaborar para a formação de sujeitos mais críticos, autônomos, conscientes de seu lugar no mundo. O público de eventos culturais muitas vezes os vê somente a partir dos produtos que ali se apresentam acabados, finalizados, prontos para fruição, ignorando, entretanto, todas as instâncias e etapas de trabalho necessárias para que se constituam como tal.

Como se disse, a publicização de um processo de produção para o público, a partir da exposição de conteúdos produzidos por seus agentes e diferentes atores, pode alimentar de informações àqueles interessados pelo assunto, conhecer o que foi feito para que aquele evento se efetivasse, pode repercutir de forma imediata trazendo novos insumos para contextualizar a experiência vivida ali, e talvez ampliar o rol de questões a serem consideradas naquela experiência, de forma individual ou coletivizada. É também possível que, a longo prazo, esse parâmetro de produção, de processo, passe a ser considerado em outras situações, como balizador de avaliações ou de juízos de valor ou, ainda, para a própria fruição. Assim, não só o produto cultural, mas seu processo de produção podem se tornar objeto de reflexão e crítica.

$\mathrm{Na}$ interface Backstage os inputs podem estar num formato textual ou, ainda, em imagens, sejam vídeos, fotografias, e outros. Mais importante, porém, que o suporte da informação, é que a partir da interação se constroem e se exploram diferentes narrativas, que podem também ser expostas na medida em que tais interações são projetadas em grandes superfícies para um grupo ou uma coletividade. A interface admite assim que várias narrativas sejam construídas a partir de enfoques distintos e opções adotadas frente a muitas possíveis. Narrativas diferentes entre si na medida em que se têm diferentes interatores, e que quando projetadas, fazem com que o público tenha acesso e possa usufruir de diferentes estórias construídas a várias mãos.

As experiências de uso da interface nessa ação do projeto mostraram-se promissoras no sentido de agregar um conjunto de informações produzidas por atores e agentes distintos de forma assíncrona, que alimentam e orientam experiências de públicos a partir de interações síncronas em contextos de eventos culturais em espaços urbanos. Nesse sentido, a interface Backstage cumpre, de certo modo, a perspectiva de sobrepor produção e produto cultural, etapas aparentemente independentes aos olhos do público.

Entretanto, seu uso específico nas experiências aqui consideradas, durante apresentações da banda de rock Topsyturvy na ação Backstage, teve êxito limitado. Os eventos musicais têm curta duração, e neles impera uma dinâmica de múltiplas atrações. 0 fato de requerer interações síncronas mais atentas e focadas do público nem sempre corresponde às condições desses eventos. Os eventos de rock são lugares em que as pessoas gostam de circular, dançar, conversar, e não necessariamente de ficar mais atentas a informações que requerem um pouco mais de atenção. Uma interação que realmente revele o que está "por trás do que você vê", como escrito na interface, demanda uma interação mais longa, detida. Ou que poderia ocorrer em eventos dessa natureza que possuam caráter mais duradouro, como festivais, com momentos de transição entre apresentações, nos quais o uso dessa interface poderia ser uma alternativa a outras atividades ali dispostas.

Ampliando ainda mais a repercussão que o uso dessa interface em ações e eventos culturais poderia ter, está a possibilidade de ter os interatores, pessoas que compõem o público, opinando sobre esse processo, através de comentários inscritos na própria interface, por exemplo. Isso sublinharia ainda mais o caráter de uma atitude ativa de um sujeito que se quer cada vez mais atuante, participativo. Tudo isso se alinha também, em certo sentido, à questão de formação de público, mas para além da questão do acesso quantitativo aos produtos e bens culturais em geral. Tratase da formação de público sob a ótica de formação crítica das pessoas que compõem esse público, e da possibilidade de ter, cada vez mais, as pessoas podendo exprimir e expor suas opiniões e pontos de vista, principalmente em espaços públicos e de uso coletivo.

\section{Interface Comentários: outros diálogos no espaço público}

A interface Comentários permite às pessoas publicizarem suas ideias acerca de um tema proposto em um evento cultural. Utilizando tablets ou laptops que circulam com agentes promotores em meio ao público, ou ainda através de telefones celulares, conectados à internet, as pessoas são convidadas a expressar-se ou expor suas opiniões através de mensagens textuais em uma interface web, que por sua vez, são projetadas, de forma síncrona, no espaço do evento. As pessoas têm a possibilidade de se identificar ou de manter-se anônimas, assinando ou não esses comentários, mas mais importante que isso parece ser a possibilidade que a interface favorece de se criar uma reflexão coletiva no espaço urbano ou de uso coletivo a partir de um tema comum.

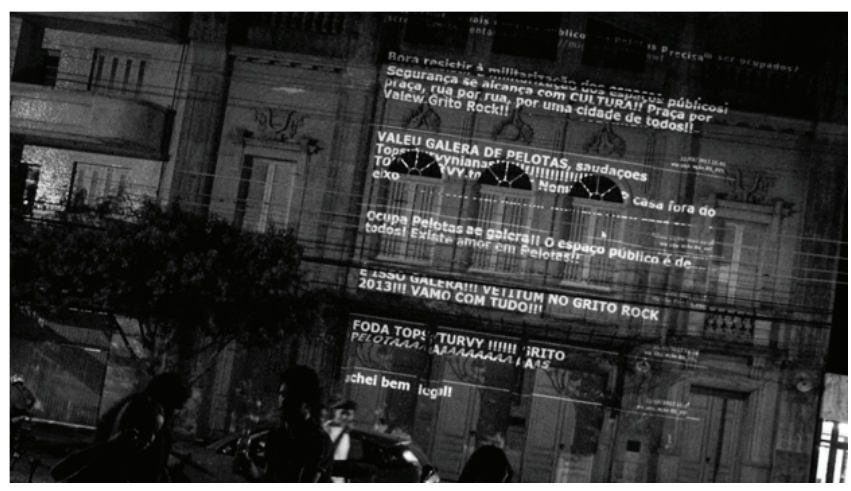

Figura 3: Interface Comentários em evento da ação Backstage em Pelotas. Fonte: Nomads.usp 
Em todas as ocasiões em que a interface foi utilizada em eventos dessa ação, foram propostos temas que tinham relação com possíveis usos dos espaços públicos urbanos. Na apresentação da banda Topsyturvy na praça central da cidade de Pelotas os comentários sobre a "Ocupação de Espaços Públicos" foram projetados na fachada de um teatro que está fechado há anos. Esse teatro possui uma representatividade simbólica na cidade, e nesse caso, a interface não só incitou o público a se manifestar sobre o evento e sobre a temática proposta, mas também colocou em evidência o próprio teatro, um equipamento público que poderia estar aberto recebendo diversas manifestações artísticas na cidade, como comentado através da interface. A interface Comentários foi projetada quase sempre em lugares em que o público e a banda pudessem ler o que estava sendo escrito. Mas não só o público presente fisicamente postava comentários. Em algumas ocasiões um público potencial foi criado por pessoas que se encontravam à distância assistindo as apresentações por livestream, e enviaram comentários através da página da interface pela internet, acessada a partir de diferentes dispositivos.

As experiências com a interface Comentários foram significativas em várias ações do projeto, despertando na maioria dos contextos utilizados grande interesse por parte do público. Percebeu-se que o enfoque dos discursos nas questões de interesse coletivo, de caráter público, depende, necessariamente, das ações de estímulo e incentivo por parte daqueles que convidam à interação através dos dispositivos móveis. O uso espontâneo mostra certa tendência de apropriação da ferramenta para a exposição de aspectos mais relacionados à vida privada das pessoas, distanciando-se da experiência do espaço urbano como esfera pública.

Ainda assim, cumpre-se a premissa de não só dar voz às pessoas, que, mesmo reunidas em eventos dessa natureza geralmente se mantêm desconhecidas entre si, e sim de ampliar essa voz para instâncias de certa visibilidade comum. De revelar, de certa forma, a diversidade dos perfis das pessoas que compõem o público, na grande maioria das vezes tomado como uma entidade homogênea e genérica.

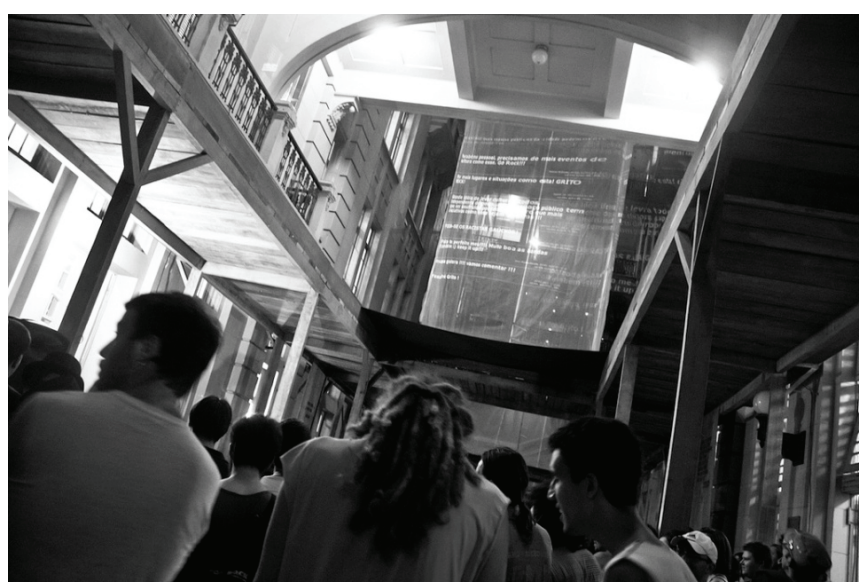

Figura 4: Interface Comentários em evento da ação Backstage em Porto Alegre. Fonte: Nomads.usp

\section{Intervindo em Espaços Públicos}

As experiências aqui relatadas com as duas interfaces em questão atestam, por um lado, que ambas se configuram como espaços democráticos, como espécies de ágoras, que propõem instâncias públicas de interação, independentemente do caráter do lugar físico no qual efetivamente são projetadas. Nesse sentido, quando projetadas em espaços urbanos, dotam-nos para além dos seus atributos físico-espaciais. Ou ainda, reforçam o caráter desses espaços como construtos delimitados por indivíduos ou grupos sociais, como locus onde se tece uma trama de relações, onde se estabelecem consensos e conflitos. Esses espaços são assim identificados como palco onde se estabelecem múltiplas interações, que podem ser ampliadas e adensadas pelos meios digitais, e pelo uso dessas interfaces em particular. Seu uso remete aos estudos apresentados por Aurigi \& de Cindio (2008), que expressam preocupações com a mudança nas maneiras das pessoas usarem a cidade e viverem nelas cotidianamente, a partir do desenvolvimento de ambientes enriquecidos pelos meios digitais, pela computação ubíqua, pelas tecnologias de comunicação móveis.

Nessa ação do projeto Territórios Híbridos, as intervenções em diferentes espaços urbanos com essas duas interfaces atestaram a importância de se considerar o espaço a partir desses componentes. Ainda que se implantassem as mesmas interfaces, em condições muito semelhantes, as intervenções realizadas se mostraram diferentes, porque pessoas e grupos de pessoas são diversos, atestando que o espaço urbano é o espaço das diferenças.

Os aportes específicos que podem ser dados aos espaços urbanos por essas duas interfaces, numa perspectiva espacial, parecem, por um lado, transformar elementos do próprio espaço físico a partir de uma aderência física aos elementos ambientais e espaciais. Por outro, estendem o espaço físico, que passa assim, a abarcar espaços informacionais remotos, que podem estar conectados de forma síncrona ou assíncrona ao universo digital das redes, favorecendo o compartilhamento de informações, interações e experiências. Nesse sentido, tais aportes se alinham às discussões teóricas nesse campo do design de interfaces para espaços urbanos, como também da constituição de espacialidades híbridas em meio urbano, como apresentam James \& Nagasaka (2011) e Weiner (2010). Foth (2009) procura delimitar e definir as pesquisas dessa natureza, que se voltam ao estudo, à concepção e à prática de experiências urbanas entre diferentes contextos urbanos, criados pelas novas oportunidades da tecnologia ubíqua, em tempo real, e pela ampliação das camadas de mediações entre o físico e o digital das redes de pessoas e infraestrutura urbanas.

Em todos esses casos, o que se viu foi o aporte dos meios digitais funcionando como aproximador de diferenças, tornando visível o que não é normalmente visível, mas ainda assim, real. 


\section{Agradecimentos}

FAPESP Fundação de Amparo à Pesquisa do Estado de São Paulo.

\section{Referências}

Aurigi, A. \& De Cindio, F. (Eds.). (2008). Augmented Urban Spaces: articulating the physical and electronic city. Hampshire e Burlington: Ashgate.

Bolter, J. D. \& Gromala, D. (2003). Windows and mirrors: interaction design, digital art, and the myth of transparency. Cambridge: MIT.

Foth, M. (Ed.). (2009) Handbook of Research on Urban Informatics: The Practice and Promise of the Real-Time City. Hershey, PA: Information Science Reference, IGI Global.
Foth, M., Choi, J. H. \& Satchell, C. (2011). Urban Informatics. In: Bardram, J.; Ducheneaut, N. (Eds.), Proceedings of CSCW 2011. Hangzhou: China.

James, A. \& Nagasaka, D. (2011). Theoretical Connection Points Between Multimedia and Architecture. Journal of Asian Architecture and Building Engineering, 10 (1), 171-178.

Preece, J., Rogers, Y. \& Sharp, H. (2005). Design da interação: além da interação homem-computador. Porto Alegre: Bookman.

Weiner, H. (2010). Media Architecture as Social Catalyst in Urban Public Spaces. In: Geelhaar, J. et al. (Eds.). MediaCity: Interaction of Architecture, Media and Social Phenomena. Weimar: BauhausUniversität 